\title{
Denetimde Önemlilik Kavramı Üzerine Bir Literatür Taraması ${ }^{1}$
}

\author{
DOI: $10.26466 /$ opus.583802 \\ * \\ Mehmet Ünsal Memiş* - Mehmet Okşaş ** \\ * Doç. Dr., Çukurova Üniversitesi, İ̈BF / Adana / Türkiye \\ E-Posta: mmemis@cu.edu.tr \\ ORCID: 0000-0003-1970-0480 \\ ** Doktora Öğrencisi, Çukurova Üniversitesi, SBE / Adana / Türkiye \\ E-Posta: mehmet.oksas@mail.com \\ ORCID: $\underline{0000-0002-4109-9866}$
}

\section{Öz}

İşletmelerin sunmuş oldukları finansal tablolar, çok geniş bir finansal bilgi kullanıcı kitlesinin (işetme yöneticileri, kredi să̆layıcılar, mevcut ve potansiyel yatırımcılar, kamu kurumları, sendikalar vb.), işletmeler ile ilgili aldıkları kararlarda rehber işlevi görmektedir. Arz ettiğgi bu önemli işlev nedeni ile finansal tabloların bağımsız denetim sürecinden geçmesi, işletmeler ile ilgili alınacak kararlara temel teşkil eden finansal tabloların güvenilirlik düzeyini tesis etmektedir. Bağımsız denetim alanında önemlilik, finansal tablolarda yer alan bilgilerdeki olası bir hata, hile ya da eksiklik, karar alıcıların alacakları kararları etkileyecek düzeyde ise önemlidir şeklinde tanımlanmaktadır. Bă̆ımsız denetim süreci için hayati önem taşıyan önemlilik düzeyinin tespiti denetçiler tarafindan yapılmaktadır ve bu düzeyin ne olması gerektiği ile ilgili genel kabul görmüş bir veri yoktur. Önemlilik düzeyi bazı durumlarda denetçilerin muhakemesine göre bazı durumlarda da denetim sürecinden geçen işletmenin yapısına ve bulunduğu sektöre göre değişiklik gösterebilmektedir. Kuramsal açıdan yürütülen bu çalışmada görece değişebilen önemlilik düzeyi ile ilgili olarak ulusal ve uluslararası literatür taraması yapılmıştır.

Anahtar Kelimeler: Önemlilik, Bağımsız Denetim, Risk Değerlendirmesi

\footnotetext{
${ }^{1}$ Bu çalışma, 02.05.2019 tarihinde OKÜ'de düzenlenen 18. UiK'de bildiri olarak sunulmuş olup bildiri kitabında genişletilmiş özet olarak yayımlanmıştır.
} 


\title{
A Literature Review on Audit Materiality
}

\begin{abstract}
The financial reports, presented by the companies, lead a role of guiding for a vast number of financial information users (Management, creditors, potential investors, government bodies, labor unions etc.) on their decision-making processes. The independent audit process of this vital function boosts the reliability of financial statements which consists the basis for a decision-making. Materiality in audit is described as; "a fraud, error or misstatement is material when it is at a level where the decisions of the users are effected". The materiality, which poses a vital role in audit processes, is defined by the auditors and has not a generally accepted formula. It depends sometimes on the professional judgement of auditors, on the anatomy of the auditee and on the spesific features of the industry at which the auditee performs. This study, being performed in a conceptual way, has experienced a literature review of both national and global sources on materiality.
\end{abstract}

Keywords: Materiality, Independent Audit, Risk Assessment 


\section{Giriş}

Önemlilik kavramının muhasebe disiplininde ifade ettiği anlamın ötesinde denetim açısından incelendiğinde ortaya açıkça konulabilen bir teorik ve pratik modellerin varsayımsal, kendine özgü ve hem nitel hem de nicel özellikler taşıdığı, bu yüzden de ne teoride ne de uygulamada bir yeknesaklıktan bahsetmenin mümkün olduğu görülmektedir.Kavramsal olarak belirsizlik sunan ve yargısal değerlendirmelere ihtiyaç duyan önemlilik kavramının bir de kullanılabilir kısıtlı veriden kaynaklı olarak akademik çalışmaların azlığı ve yeterli açıklama içerememesi sorunlarına sahip olması bu kavramın daha fazla araştırılmasını gerekli kılmaktadır.

Ülkemizde de bu kavramla ilgili akademik çalışmalar daha çok bir uygulama rehberi sunmak amaçlı yapılmış, yukarıda bahsedilen veri yetersizliği sebebiyle bu kavramla ilgili olarak uygulamaya yönelik yeterli çalışma ortaya konulamamıştır.Bu sebeple çalışmamızda önemlilik kavramı üzerinde bir literatür taraması yapılarak önemliliğin kavramsal çerçevesini, özellikle uluslararası düzeyde yapılan çalışmalarda kullanılan araştırma yöntemlerini, uygulanan nitel ve nicel modeller ile araştırmalar sonucu elde edilen çıkarımları özet bir şekilde ortaya koymak amaçlanmıştır.

\section{Önemlilik Kavramının Tarihi Gelişimi}

Günümüzde muhasebe alanında kullanılan önemlilik standartları İngiliz genel hukukundan doğmuştur. Mesela 1867'deki Venezuela Merkezi Demiryolları (Central Railway of Venezuela) davasında İngiltere'de verilmiş olan mahkeme kararı önemlilikle ilgili şu gerekçeyi ortaya koymuştur:“...hiçbir önemli gerçeğin yanlış bildirimine veya gizlenmesine müsaade edilmemelidir." Önemlilik konsepti ABD'de 1800'lerin sonundan itibaren yasalaşmış ve bugüne dek finansal sunumun temel parçalarından biri olmuştur (Eilifsen ve McKee, 2000, s.50).Daha önce uygulandığı gibi muhasebecinin yargısına dayanmaktansa daha elle tutulur bir önemlilik testi geliştirme çabalarına 1970'lerde şahit olunmuştur. Bugün de devam eden ve bu çabalardan ortaya çıkan tartışma önemliliğin nicel ya da nitel bir standarda dayanıp dayanmaması gerekliliğidir (Park, 2009, s.524). 
1980'ler boyunca hem mahkemeler hem de ABD Menkul Kiymetler ve Borsalar Komisyonu (SEC-Securities and Exchange Commision) önemliliğin nitel konseptini reddeder görünmekle beraber 1998' de SEC başkanı Arthur Lewitt "Sayılar Oyunu" konuşmasında şirketlerin önemlilik kavramını kötüye kullanarak kazançlarını yüksek göstermeye çalıştıklarını ileri sürerek önemliliği nicel bir Standart olmaktan çıkararak ve yatırımcının kararını etkileyebilecek bütün ilgili etmenleri hesaba katabilecek bir önemlilik değerlendirmesi yaparak kazanç yönetimi ile mücadele etmeyi önerdi (Park, 2009, s.526). Özellikle bu öneri ve arkasından gelen Sarbanes Oxley yasası önemlilik kavramına yeni işlevler yüklemiş, standartlar kapsamında da önemlilik tekrar gündeme gelmiştir.

\section{Önemlilik ve Denetim}

Denetim mesleğinin doğası gereği önemliliğin doğru kullanımıyla denetim yükü azaltılabilir ve iş ağırlığı olarak daha isabetli seçimler yapılabilir. Önemlilik basitçe göreceli ehemmiyettir (Barnes, 1973, s.79).

Finansal tabloların önemli yanlışlık içermediğini yönetim ileri sürer ve denetçiler doğrular (Dutta ve Graham, 1998, s.151).Önemlilik bir denetimin kapsamının planlanması ile ilgilidir ve makul güvence için gerekli denetim prosedürlerinin doğası, derinliği ve zamanlamasını etkiler (Raman ve Van Daniker, 1994, s.74).Denetim önemliliği (kapsam belirleme planlamasında kullanıldığı şekliyle) ile muhasebe önemliliği (önemli yanlışlık içeren finansal tablolarda gözden kaçan uyarlamalar için bir eşik değer sınırlaması olarak) arasındaki ayrım mühimdir.Yine de muhasebe tanımları yanlış bir şekilde denetim amaçlı kullanılmakta, aralarındaki ayrım ne açık bir şekilde ortaya konmuş ne de denetim literatüründe tanımlanmış veya erişime açık kaynaklarda tartışılmıştır. Basitçe açıklamak gerekirse muhasebe önemliliği, tespit edilmiş olan bilinen ve öngörülen yanlışlıklara karar vermede denetçiye yardım ederken; denetim önemliliğinin amacı denetçinin ne kadar yanlışlık aramaya ihtiyacı olduğu konusunda bir çerçeve sunmaktır. İlişkili kavramlar olsalar da muhasebenin ve denetimin kullandığ 1 'önemli' ve 'önemlilik' birbirinden çok farklıdır (Jacoby ve Levy, 2016, s.17).

Denetçiler finansal tablo kullanıcısı olmamakla beraber önemliliği değerlendirmek zorundadırlar (Chen ve Tsay, 2017, s.56). 
Uygulamada denetçiler önemliliği denetim testlerinin gerekli kesinliğini ve finansal tablolarda düzeltme gerektirecek yanlışlıkları tespit etmede kullanmaktadırlar. Denetçiler kazançlarda ve/veya diğer hesaplarda önemli yanlışlığa sebep olabilecek yanlışlıkların boyutunu dikkate almaktadırlar.

Daha önceki çalışmalar denetçiler tarafından kullanılan üç nicel ölçüt ortaya koymuştur. Bunlar;

- Gelirin yüzdesi

- Satışlar ya da toplam gelirlerin yüzdesi

- Toplam varlıkların yüzdesi (Cho vd., 2003, s.64)

Önemlilik öznel bir kavramdır.Bir durumda önemli olan bir diğerinde olmayabilir.Denetçinin belirleyeceği önemlilik düzey veya düzeyleri denetçinin mesleki yargı ve tecrübesine bağlıdır.Denetçinin belirleyeceği önemlilik finansal tablo kullanıcılarının ihtiyaçlarını algılama şekli ve düzeyinden etkilenmektedir (Socol, 2008, s.209).Neyin önemli neyin önemli olmadığı konusu gündeme geldiğinde zorluklar ortaya çıkmaktadır (CICA, 1978, s.2). Önemliliğin ne kadar veya ne olduğunun belirlenmesi, finansal raporlama ve açıklama seçimlerinin finansal tablo kullanıcılarının kararları üzerindeki göreli önemi ve etkisi hakkında profesyonel yargıyı gerektirir (Erdoğan, 2007, s.119).

Standartların ilke tabanlı olması yerine kural tabanlı olması gerektiği yönünde ve aleyhindeki iddialar yıllarca süregelmiş ve bugün de devam etmektedir.Kural tabanlı standartları destekleyenler genellikle standartlar için çok teknik olma durumunu gündeme getirmektedir. Her ne kadar ilke tabanlı standart anlayışı denetçi yargısına daha fazla imkân tanısa da denetçilere önemlilik ve örneklem alanlarında çok daha elle tutulur ve tutarlı uygulamalar sağlamasından ötürü araştırmacılar tarafından kural tabanlı standart anlayışı ağır basmaktadır (Jacoby ve Levy, 2016, s.17).

\section{Denetimde Önemlilik Düzeyinin Kullanılması}

Denetçiler her denetimde önemlilik yargısında bulunmak zorundadırlar. $\mathrm{Bu}$ sürecin zorluğu hem nicel hem nitel etmenlerin değerlendirilmesini içermesidir. İlave olarak önemlilik konseptinin nasıl uygulanacağı hususunda standartlar yol göstermemektedir (Eilifsen ve McKee, 2000, s.54). Vaassen (1994)'e göre denetçi kendisini finansal tabloların bir rasyonel 
okuyucusu olarak görmekte ancak bir rasyonel okuyucu ise finansal tabloları incelerken önemlilik düzeyini denetçi kadar dikkate almamaktadır. Bir kez denetçi görüşü verildiğinde artık finansal tabloların devam eden iş süreçleri için doğru ve gerçek bilgi sunduğu kabul edilmektedir. İşte burada denetçi rasyonel okuyucuların hangi kararları almak için finansal tabloları incelediğini hesaba katmak zorundadır. Böylece önemlilik düzeyi belirlemede bir niceliksel yaklaşım zorunluluğu ortaya çıkmaktadır ve fakat bugüne kadar bu mümkün olmamakla beraber gerek denetim firmalarının gerekse uluslararası kuruluşların rehber niteliğindeki yayınları ortaya çıkmıştır.

Finansal Raporlamaya İlişkin Kavramsal Çerçeve (2018)'de önemlilikle ilgili olarak "Bir bilginin verilmemesi veya yanlış verilmesi genel amaçlı finansal raporların asli kullanıcılarının belirli bir raporlayan işletmeye ilişkin finansal bilgileri sağlayan finansal raporlara dayanarak vereceği kararları etkileyebiliyorsa bu bilgi önemlidir" (http://kgk.gov.tr) denilerek muhasebe açısından önemlilik kavramına atıf yapılmakta; "önemlilik, belirli bir işletmenin finansal raporu bağlamında bilgilerin ilgili olduğu kalemlerin yapısı veya büyüklüğüne ya da her ikisine dayalı olan ihtiyaca uygunluğun işletmeye özgü yönüdür" (http://kgk.gov.tr) denilerek bu kavramın standart bir ölçü ile kısıtlanamayacağı, her işletme ve sektör bazında farklılık gösterebileceği vurgulanmıştır.

Her iki konsept için de önemliliği belirleyen baskın unsur müşteri de dahil olmak üzere finansal tablo kullanıcılarının ihtiyaçlarıdır. Eğer kullanıcılar öncelikle kazanca odaklanmışlarsa önemlilik vergi öncesi gelire, faiz öncesi gelire veya diğer kazanç ölçülerine bağlı olmalıdır. Eğer kullanıcılar öncelikle nakit akışlarına odaklanmışsa önemlilik nakit akışını esas alan bir ölçü ile belirlenmelidir. Denetçinin mesleki yargısı ilk önemlilik tahmininde anahtar roldedir (Read vd., 1987, s.73).

\section{Önemlilik Düzeyinin Belirlenmesi}

Porter vd. (2003)'ne göre önemliliğin 4 özelliği bulunmaktadır:

- Neyin önemli olup olmadığı her durumda mesleki yargıya bağlıdır.

- Nicel veya nitel önemlilik söz konusu olmaktadır. 
- Önemlilik yasal veya düzenleyici ihtiyaçlara göre değişebilmektedir.

- Önemlilik iki seviyede göz önüne alınmalıdır;

- Bütüncül seviye: finansal tabloların tamamina göre ve

- Hesap seviyesi

Önemlilik kavramının anlamından da anlaşılacağı üzere denetim sırasında neyin önemli olduğu konusunda karar verebilmek için denetçiler bir yargıya varmak zorundadırlar.

Aslında önemlilik değerlendirmesi, önemli yanlışlıkların boyutundan bağımsız olarak birçok niteliksel etmen içermektedir (Comunale ve Sexton, 2005, s.3).

Önemlilik kavramını risk değerlendirmesinden bağımsız düşünmek mümkün değildir. Bir denetçi önemlilik ve riski şu amaçlar için göz önünde bulundurmalıdır (McConnell ve Schweiger, 2007, s.21);

- Risk değerlendirmesinin doğası ve genişliğine karar vermek

- Önemli yanlışlık risklerini tanımlamak ve değerlendirmek

- Sonraki denetim prosedürlerinin doğası, zamanlaması ve kapsamina karar vermek

- Finansal tabloların gerçeğe uygun olarak sunulup sunulmadığını değerlendirmek

Kesimli (2018) önemlilik ve önemli riskler kapsamında yapılan değerlendirmelerin denetimin kalite kontrol süreçlerinde gözden geçirilebileceğini belirtmektedir. Hem teorik hem de pratik bakış açısıyla denetim riski, uygun birönemlilik düzeyi ele alındığında anlamlı bir hale gelir. Önemlilikve denetim riski, denetçinin kanıt kararları üzerinde önemli etkiyesahiptir.Denetçi hem denetim yordamlarının yapısını, kapsamını ve zamanlamasını planlamada hem de bu yordamların sonuçlarınıdeğerlendirmede her iki kavramı da dikkate alır (Kızılgöl ve İşgüden, 2011, s.9).

Planlama önemliliği kabul edilen maksimum denetim riski seviyesine bağlı olarak denetçinin denetim görüşünü etkilemeyen tanımlanmış veya tanımlanmamış bütün önemli yanlışlıkların maksimum toplam değerini (tek bir örneklem uygulamasında hoşgörülebilecek önemli yanlışlıklar gibi) ifade eder. Bu kapsamda hoş görülebilecek maksimum toplam önemli yanlışlık, hem bilinen hem de öngörülen önemli yanlışlıklar ile tahmini bilinmeyen veya tespit edilmemiş önemli yanlışlıkları içerir.Denetim \%100 lük bir bilgiden azını dikkate aldığından bilinmeyen önemli 
yanlışlık riski her zaman mevcuttur (Jacoby ve Levy, 2016, s.16). Denetçi planlama aşamasında aşağıda belirtilen konularda bir dayanak oluşturmak amacıyla yanlışlıkların büyüklüğü konusunda yargıda bulunmalıdır:

- Risk değerlendirmenin kapsamı, yapısı ve zamanlaması

- Önemli yanlışlık riskinin tanımlanması ve değerlendirilmesi

- Denetim prosedürlerinin yapısı, zamanlaması ve kapsamının belirlenmesi (Cömert, 2012, s.33).

Testler sırasında denetçinin göstereceği çaba genellikle belirlenen planlama önemlilik düzeyi ile bağlantılı olduğundan denetim programının tasarımı sırasında denetçi tarafından ortaya konan planlama önemlilik düzeyinin belirlenmesi denetçinin yargısına dayanan önemli bir süreçtir. Buna rağmen mesleki rehberler planlama önemlilik düzeyinin belirlenmesi konusunda çok net bilgi sunmaz (Blokdijk vd., 2003, s.297).

Eilifsen ve McKee (2010) önemlilik düzeyinin belirlenmesine yönelik olarak spesifik yaklaşımları şu şekilde sıralamıştır: yargısal yaklaşım, oran yaklaşımı, girilen düzeltmeler yaklaşımı, formül yaklaşımı. Öte yandan bu yaklaşımları etkileyen nitel etmenler ise; maliyet, analitik prosedür sonuçları, hesaba ait önceki düzeltmeler, yanlışlıkların sonuçları ve hesap bilgisinin başkaca amaçlarla kullanımı şeklinde sıralanmaktadır.

Önemliliğin nicel hale getirilmesinde birçok tanım muhtemel yöntemler sunmakta, planlama amaçları için farklılaşan tutarlarda sonuçlar ortaya koymaktadır (Pany ve Wheeler, 1989, s.71).

Denetim açısından bakıldığında önemliliğin ölçülmesinde hangi ölçütlerden hareket edileceği hakkında kesin bir şey söylemek çok zordur. Bununla birlikte yapılan bir araştırmaya göre, denetçilerin önemlilik konusunda karar alırken aşağıdaki değişkenlere başvurdukları saptanmıştır:

- İlgili kalemin türü

- İlgili kalemin cari yıl net karına oranı

- İlgili kalemin toplam hasılata veya giderlere oranı

- İlgili kalemin net çalışma sermayesi üzerine yapacağı etki

- Kazançların büyüme hızı

- İlgili kalemin kazançların yükselme eğilimini ters yönde etkileyip etkilemediği

- İlgili kalemin mutlak tutarı 
- Hisse senetleri fiyatına olan etkisi (Çakıcı, 2002, s.75).

Uluslararası Bağımsız Denetim Standartları (BDS) 320'de yer alan açıklamalardan görüleceği gibi, denetçiler önemlilik düzeyinin tespitinde farklı yaklaşımlar kullanabilirler, önemli olan işletmeye ve çevresine en uygun kriterin tespitidir (Taş ve İnaltong, 2015, s.80).

\section{Literatür}

Önemlilikle ilgili gözlemlenen bir gelişme de kullanılan metodolojidir.İlk zamanlarda birçok önemlilik araştırmasında anket ve arşiv çalışmaları yer almış, son zamanlarda bu eğilim deneysel yaklaşım yönünde ilerlemiştir.Araştırmacılar günümüzde önemlilik kararlarında karmaşık süreçlerin varlığını kabullenmişlerdir (Iskandar ve Iselin, 1999).Bu çalışmada gerçekleştirilenliterature taramasında Teori ve Uygulama ayrımı esas alınarak bir sınıflandırma yapılmıştır.

\section{Teori}

Taş ve İnaltong (2015) önemlilik kavramını açıklamakla kalmayıp planlama ve uygulama aşamalarında önemlilik düzeyinin nasıl belirlendiğini hem teorik olarak hem de bir örnek uygulama sunmak yoluyla ülkemizde kabul görmüş önemlilik düzeyi oranlarını kullanarak somut olarak göstermişlerdir.

Cömert (2012) önemlilik düzeyi hesaplama yöntemlerini dört başlık altında toplamış, BDS'lerde herhangi bir düzey belirlenmediği için genel olarak kabul gören oranlar üzerinden örnekler yoluyla bir rehber olarak alınabilecek şekilde açılamıştır.

Erdoğan (2007) önemlilik düzeyinin niteliksel boyutunu mevcut düzenlemeler 1şığında incelemiş, standartların niteliksel önemlilik kavramını açıklamakta ve denetçilere yol göstermekte yetersiz kaldığına dikkat çekmiş, denetçinin mesleki yargısının nitel önemlilik uygulamalarında anahtar role sahip olduğunu vurgulamıştır.

Karavardar (2014) grup denetimlerinde önemlilik düzeyi belirlenmesine ilişkin uygulamalı bir çalışma yapmış, GUAM ile MACM metotlarını uygulama sonuçlarına göre karşılaştırmıştır. 
Kızılgöl ve İşgüden (2011) denetim riski belirlenirken denetçiler tarafından kullanılan mesleki yargıyı incelerken önemliliğin denetim riski ve denetim kanıtı ile olan ilişkisine de açıklık getirmiştir.

Terzi (2012) önemlilik düzeyinin belirlenmesinde ‘bulanık mantık yöntemi'nin kullanılmasını araştırmış, belirsizlik durumlarında çeşitli nicel ve nitel faktörlere dayanan bu yöntemi bir uygulama çerçevesinde ele alarak açıklamıştır.

Socol (2008) önemlilik düzeyi belirlenirken denetçinin mesleki yargısını kullanması ve öznellik (subjectivity) üzerinde durmuş, bu kavramların önemlilik düzeyi belirlemede hayati derecede önemli olduğunu belirtmiş ve günümüzde şirketlerin çaplarının büyümesi neticesinde önemlilik kavramının daha da gerekli olduğu sonucuna varmıştır.

Brody vd. (2003) Enron'un 1997'deki net kar düzeltmesinin (105 milyon \$'dan 51 milyon \$'a düzeltme) önemli olup olmadığını aynı yıl geçerli olan ancak yasal olarak uygulama zorunluluğu bulunmayan uygulama rehberlerine göre değerlendirerek bu düzeltme sonucunda denetim raporunun değiştirilebileceğini ve hatta denetim raporunda olumsuz görüş verilebileceğini irdelemiş, sonuçta söz konusu rehberlerde ilave iyileştirmeler yapılması gerektiğini vurgulamıştır.

Budescu vd. (2012) denetim kanıtı, önemlilik ve denetim riskinin ortak etkisini araştırarak, denetimin kesinlik seviyesini arttırmaya yönelik olarak önemlilik seviyesini düşürmenin denetim sonuçlarında gelişime yol açabileceği gibi denetimin tamamını tehlikeye atabileceği sonucuna ulaşmıştır. Eilifsen ve McKee (2000) önemlilik kavramının tanımı itibariyle mesleki yargıya bağımlı olmasından yola çıkarak henüz tanım aşamasında kendi içinde sorunlu olduğunu vurgulamış, buna rağmen günümüzde önemlilik ile ilgili sorunların konseptten değil uygulamalardan kaynaklandığını savunmuştur. Comunale ve Sexton (2005) ‘bulanık mantık' (fuzzylogic) modelini önemlilik düzeyi belirlemede kullanılmak üzere önermiş, önemlilik derecesi için 0 ile 1 arasında nicel bir ölçeklendirme yapmış, yanlışlıkların önemlilik değerlendirmesinde hangi yanlışlıkların daha önemli olduğu ve ilave araştırma gerektirdiği hususlarında kılavuz görevi gördüğünü ileri sürmüştür.

Douglas (2017) hazırladığı yüksek lisans tezinde Yeni Zelanda'da faaliyet gösteren halka açık şirketler tarafından açılanan önemlilik düzeylerinin yatırımcı üzerine etkilerini araştırmış, yüksek belirlenen önemlilik 
düzeylerinin profesyonel olmayan yatırımcıları şirket hisselerinden vazgeçerek devlet tahvillerine yönelttiği sonucuna varmıştır.

Dutta ve Graham (1998) her hesap için önemlilik düzeyi belirlerken kullanıcı önemliliğini ve ilgili maliyet varsayımlarını hesaba katmak amacıyla çeşitli kombinasyonları (toplamlar ve oranlar) önemlilik ve denetim riskine dayanan istatistiksel bir metot geliştirmiştir.

Iskandar ve Iselin (1999) önemlilikle ilgili bir literatür çalışması gerçekleştirmişler, bu kavramın gelişimini ve akademik çevrede ele alınışını göze çarpan özellikleriyle ortaya koymuşlardır.

Canadian Institute of CharteredAccountants (1978) tarafından ilk baskısı 1965'te yapılan çalışmada önemlilik kavramının muhasebedeki kullanımıyla beraber denetim alanına yapacağı katkıyı açıklamış, önemlilik düzeyi belirlerken her denetimin diğerlerinden ayrı olarak değerlendirilmesi gerektiğini vurgulamış, örneklem seçimi ile önemlilik düzeyi arasındaki ilişkiyi ve önemlilik düzeyi belirlemede kullanılabilecek ölçekleri açıklamaya çalışmıştır.

Messier vd. (2005) Levitt tarafından 1998'de New York Üniversitesi'nde yapılan 'Sayılar Oyunu' (Numbers Game) konuşmasında bahsettiği bazı şirketlerin birçok önemli yanlışlı̆̆ belirlenen önemlilik düzeyinin altında tutarak kötüye kullandıkları sözlerine atıf yaparak bu konuşmadan sonra SEC'in SAB 99 ile ve beş büyüklerin ise özel bir komite kurarak sonuçta ASB'nin SAS No.89 ve No.90 ile Levitt'in iddialarını gidermeye yönelik tedbir getirdiklerini ortaya koymuş ve devamında da Holstrum ve Messier tarafından 1982'de önemlilik kavramı ile ilgili yapılan gözden geçirme çalışmasını yenilemiştir.

Morris ve Nichol (1988) finansal tablo açıklamalarında yer alan tutarlılık ilkesinin ihlal edildiği durumlarının önemlilik yargısı ve denetim sürecinin yapısı ile ilişkisini araştırmış, denetim görüşlerinin finansal tablolarla açı bir ilişkisi olduğu, bu tür denetim görüşleriyle ilgili 8 Büyüklerin kendi aralarında korelasyon olmadığı ve 8 Büyük denetim firmasının sahip olup kullandığı denetim şablonlarının söz konusu denetim görüşlerinin ortaya çıkmasına doğrudan etki ettiği sonuçlarına ulaşmıştır. Pany ve Wheeler (1989) kullanılagelen 5 önemlilik hesaplama yöntemini karşılaştırmış, hesaplamaların sektöre göre ve bu yönteme göre değişkenlik gösterebileceğini belirtmiştir. 
Roberts ve Dwyer (1998) denetim mesleğine yönelik eleştirilerden önemlilik ve makul güvence kapsamında olanları incelemiş, bu kavramların denetçiler tarafından sorumluluklarının halka açıklanma aracı olduğunu ve aynı zamanda denetçilerin yaptıkları işin ana kaynağ 1 olduğunu vurgulamıştır. Bir kısım rehberlerin, uygulama raporlarının ve akademik çalışmaların gözden geçirilmesi ile bu iki anahtar kavramın denetim uygulamalarında ne üzerinde durulduğu ne de tutarlı bir şekilde uygulandığı sonucuna varmışlardır.

Thomas ve Krogstad (1979) önemlilik kavramının felsefi, psikolojik, ekonomik ve hukuki yönlerini inceleyerek çok boyutlu doğasını vurgulamış, önemlilik düzeyi belirlemede bazı yüzde kullanımlarının yasa haline gelmesine şiddetle karşı çıkmış ve mesleki yargının nasıl kullanılabileceğine yönelik sekiz maddelik bir rehber ortaya koymuşlardır.

Seidler (1999) daha önce denetçilerin müşterilerinden düzeltilmesini istedikleri önemli olarak değerlendirdikleri yanlışlıkların müşteri işletme tarafından zaman darlığı veya zor olarak nitelendirmekten dolayı reddedilmesinin bilgisayarlar sayesinde artık tarihe karıştığını belirtmiştir.

Vorhies (2005) Sarbanes Oxley ile önemlilik kavramına yüklenen işlevleri 4 başlık altında toplayarak denetçilere açılamaya çalışmış; önemli yanlışlıklar, iç kontrol yetersizlikleri, muhasebe tahminleri ve hile olarak sıraladığı 4 perspektiften önemlilik değerlendirmesi yapılması gerektiğini belirtmiştir.

\section{Uygulama}

Chewning, Wheeler ve Chan (1998) 1980'li y1llarda gerçekleştirilen diş borç/yatırım takası (equity-for-debtswap) işlemlerinde hem denetçiler hem de yatırımcılar için önemlilik düzeylerini incelemiş, bu işlemlerden elde edilen gelirlerin denetçiler tarafından önemlilik düzeyi belirlemede dikkate alındığı sonucuna ulaşmışlardır.

Cho vd. (2003) denetçiler açısından değil yatırımcılar açısından önemlilik düzeylerini tespit etmeye yönelik olarak örneklem üzerinden inceleme ve analiz yapmış, bunu yaparken vergi öncesi kazanç, satışların yüzdesi ve toplam varlık yüzdelerini önemlilik kriteri olarak kullanmışlardır. Ortaya çıkan sonuçlar eğitimlerde kullanılan önemlilik 
düzeylerinden çok daha aşağıdadır.Bu sonuçlara göre denetçilere daha düşük önemlilik düzeyi belirleme tavsiyesinde bulunulmuştur.

Blokdijk vd. (2003) Hollanda' da faaliyet gösteren 5 büyükler ile bunun dışındaki denetim şirketlerinin 1998-99 yıllarında gerçekleştirdikleri denetimlerden oluşan bir örneklem üzerinde planlama önemliliğinde kullanılan değerleri incelemişlerdir.Planlama önemliliğinin müşteri boyutu ile giderek azalan bir oranda yükseldiğini tespit etmişler, buna ilave olarak 5 büyüklerin diğerlerine oranla daha düşük önemlilik düzeyi değerleri kullandıklarını ortaya koymuşlardır.

Emby ve Pecchiari (2013) Kanada'da faaliyet gösteren 94 denetçi üzerinde denetim standartları ve literatür tarafından performans önemliliği tahminleri hakkında önerilen çeşitli nitel risk faktörlerinin etkilerini saha çalışması şeklinde test etmiştir. "İyi" ve "kötü" versiyonları olan 6 nitel risk faktörünün 4 senaryo içerisinde kullanıldığ bu çalışma katılım sağlayan denetçilerin risk faktörlerine bağlı olarak performans önemlilik düzeyinde düzeltme uyguladıklarını göstermiştir.

Estes ve Reames (1988) denetimin kalitesini etkileyen unsurlardan kişisel özelliklere yoğunlaşmış, kısa ve uzun vadeli olarak ikiye ayırdığı kişisel özelliklerden yaş, cinsiyet ve tecrübeyi içeren uzun vadeli olanın önemlilik kararlarına olan etkisini ölçmüş, tecrübenin bu önemlilik kararlarına güveni oldukça arttırdığı, cinsiyetle ilgili tatmin edici bir yargıya varılamadığı ve yaşın muhafazakâr davranışı desteklediği sonuçlarına varmıştır.

Jordan vd. (1995) tutarlılık ilkesinin ihlal edildiği durumlarda denetçilerin raporlarında değişiklik yapıp yapmamaya karar verirken önemlilik yargısını göz önüne alıp almadıklarını araştırmışlar, 1988 ile 1992 yılları arasında Moody's sektör endeksinde yer alan 2000 firmadan 840'ının -büyüklükleri 250 bin \$ ile 193 milyon \$ arasında değişen- muhasebe ilkelerinde değişiklik yaptıklarını bildirdiğini tespit etmiş, ancak bunların sadece 72 'sinin $(\% 8,6)$ standart rapor sunarak değişiklik yapmadığından bahisle çoğu denetçinin raporlarında değişiklik yaparken önemlilikle ilgili ilave bir çalışma yapmamış olduğu sonucuna varmış, sonrasında tutarlılık ihlali durumlarında denetim raporunda değişiklik yapıp yapmamaya karar verilirken kullanılabilecek bir önemlilik değerlendirme yöntemi önermişlerdir. 
Price ve Wallace (2002) kamu sektörü kapsamındaki denetimlerde kullanılan önemlilik kavramı üzerine araştırma yapmış, araştırmaya dahil edilen ABD, Avustralya, Kanada, Yeni Zelanda ve Birleşik Krallık'tan sırasıyla 767, 609, 452, 424 ve 250 doküman incelenmiş, kullanılan bilimsel kelimelerden rehberlere kadar geniş bir yelpazede önemlilik kavramının kullanımı üzerinde durulmuştur.

Tuttle vd. (2002) belirli düzeylerdeki önemli yanlışlık içeren finansal tablolar ile bunları içermeyen finansal tabloların piyasa fiyatlarında değişikliğe sebep olup olmadığı konusunu araştırmış, bilgisayar ortamında oluşturulan her biri 12'şer tane 3 dakikalık işlem içeren 12 varlık piyasasında 6 piyasa oyuncusu tarafından gerçekleştirilen hareketler incelenmiş, önemlilik düzeyinin altında belirlenen önemli yanlışlıkların piyasadaki kullanıcıların kararlarının etkilemediği, önemlilik düzeyi üzerinde belirlenen önemli yanlışlıkların bu kararları etkilediği doğrulanmıştır.

Waters ve Tiller (1997) 37 sektörde faaliyet gösteren 130 şirketin denetim sonuçlarında yer alan sektör bilgisi, vergi öncesi net kar, varlıklar ve denetçinin belirlediği önemlilik düzeyi bilgilerini alarak öncelikle en küçük kareler regresyonu olmak üzere bir dizi regresyon modelleri kullanmış ve şirket net geliri, şirket varlık büyüklüğü ve şirket sektör geliri bağımsız değişkenleri üzerinden yorum ve sonuçlara ulaşmışlardır.

Vaassen (1994) denetim kavramını irdeledikten sonra risk değerlendirmesi ve denetim riski modellerini önemlilik düzeyi belirleme ile beraber ele almış, önemlilik düzeyi belirlemede mesleki yargı üzerinde durmuş, bunu yaparken kişilik değerlendirmelerinin teknik yönlerine ve davranışsal ölçümlere yer vermiş ve Hollanda'da faaliyet gösteren 4 büyük denetim firmasından 25 denetçiye çeşitli testler uygulayarak önemlilik düzeyi ve risk değerlendirme faaliyetlerinde mesleki yargııı ölçümlemeye çalışmıştır.

Bates vd. (1982) 67 denetçi üzerinden araştırma yaparak rotasyonun önemlilik düzeyi belirlemedeki etkisini ölçmeye çalışmışlardır.Rotasyona tabi olmayan denetçiler diğerlerine oranla yaklaşık 2 kat daha fazla önemlilik düzeyi belirlemişlerdir ki bu da yıllar itibariyle denetçi ile şirket arasında denetçinin mesleki yargısını olumsuz etkileyecek belirli bir güven ilişkisinin ortaya çıktığını göstermektedir. 
Benneth ve Hatfield (2017) zaman kısıtının denetçi üzerinde baskı oluşturarak iç kontrolle ilgili önemlilik düzeyinin yüksek belirlenip belirlenmediği üzerine 123 denetçiyi temel alarak araştırma yapmışlar, zaman baskısının düşük olduğu dönemlerde denetçilerin iç kontrol zayıflıklarını önemli gördüklerini, zaman baskısının yüksek olduğu dönemlerde bunları daha az önemli olarak değerlendirdiklerini ortaya koymuşlardır.

\section{Sonuç}

Bu çalışmada 6'sı ulusal 16'sı uluslararası düzeyde 22 teorik çalışma ile tamamı uluslararası düzeyde 13 uygulama çalışması olmak üzere toplamda 35 çalışma kullanılarak önemlilik kavramıyla ilgili yaşanan gelişmeler ve geliştirilen bakış açıları ortaya konulmuştur. Uygulamaya dönük çalışmaların ülkemizde çok az olması, yine aynı şekilde uluslararası düzeyde de sinırlı sayıda yapılabilmiş olması önemlilik kavramıla ilgili öncelikle bir veri tabanı oluşturma ve daha sonra veriye ulaşım imkânlarının sınırlı olduğunu göstermektedir.

Christensen vd. (2018)'nin de belirttiği gibi önemlilik düzeyinin denetim raporunda belirtilmesi konusunda Uluslararası Denetim ve Güvence Standartları Kurulu (IAASB-International Auditing and AssuranceStandards Board) bir zorunluluk getirmezken, ABD'nin düzenleyici kurumu (PCAOB-Public Company Accounting Oversight Board) ile Amerikan Sertifakalı Kamu Muhasebecileri Enstitüsü (AICPA-American Institute of Certified Public Accountants) kendi standartlarında böyle bir içerikten bahsetmemiş, İngiltere ve Hollanda'nın düzenleyici kurumları zorunluluk getirmiştir. Özellikle uygulamaya dönük çalışmaların çoğunun İngiltere ve Hollanda kaynaklı olması önemlilik araştırmalarında veri bulma ve veriye erişimin birinci derecede etken olduğunu göstermektedir.

Denetimlerde genel sabit bir önemlilik düzeyinin veri olarak alınamaması nedeniyle büyük ölçüde denetçiler tarafından subjektif olarak belirlenmekte olan önemlilik düzeyinin tespiti önem arz etmektedir.Gerçekleştirilen denetimlerin titizliği açısından son derece önemli olan önemlilik düzeyinin -İngiltere ve Hollanda' da olduğu gibi diğer ülkelerde de denetim raporlarında yer alması finansal bilgi kullanıcıları açısından daha faydalı olacaktır. 


\title{
EXTENDED ABSTRACT
}

\section{A Literature Review on Audit Materiality}

\author{
Mehmet Ünsal Memiş - Mehmet Okşaş \\ * \\ Çukurova University
}

Beyond its conceived meaning in accounting discipline, materiality shows no robustness both in theory and in practice as it covers numerous features of both qualitative and quantitative when observed from audit perspective. Materialty, which presents uncertainty and requires judgemental procedures, needs to be more researched because of scarcity of its literature stems from minimal exploitable data.

Materiality research in Turkey mostly focuses on burdening a role as an application guide and is not able to reflect its way of practice regarding the aforementioned data deficiency. This paper aims to present the conceptual framework of materiality, the research methodology of and the applied qualitative and quantitative models in international literature. Literature review in this paper is classified into two as theoretical and practical.

Methods used in determination of materiality is a basic novelty. Methodology has converged from archive and survey to experimental perspective. Researchers has recently admitted the presence of complex processes in materiality decisions (Iskandar\&Iselin, 1999, s.229). This paper fundamentally made a classification of theory and application.

Erdoğan (2007) has examined the qualitative side of the materiality level on the basis of present regulations, has claimed that the standards are not sufficient in describing the qualitative materiality and has asserted that auditor's professional judgement plays a key role due.

Kızılgöl and İşgüden (2011) clarifies the relationship between materiality and 'audit risk and audit evidence'.

Socol (2008) focuses on subjectivity and auditor's usage of his/her professional judgement while determining materiality level and asserts that 
the importance of materiality increases as the size of companies grows more and more.

Brody, Lowe ve Pany (2003) studied on Enron's correction of its net profit (from $\$ 105$ million to $\$ 51$ million), asked whether that correction amount was material or not, and asserted that it was possible to review the audit report and even to issue an adverse opinion.

Comunale ve Sexton (2005) recommended to adapt fuzzy logic model on determining the materiality level, prepared a quantitative scale between 0 and 1 .

Douglas (2017), in his masters thesis, examined the affect of materiality disclosures of public companies in New Zealand on investors and found that high level of materiality disclosures convince the investors to move from stocks to government bonds.

Dutta ve Graham (1998) developed a statistical model, which relies on varous combinations of materiality and audit risk, for taking user's materiality and cost assuptions into account.

Morris ve Nichol (1988) studied on the relationship between materiality judgement and characteristic features of audit process when the principle of consistency situated in financial disclosures is violated. They inspected a robust correlation between the audit opinions and financial statement disclosures however materiality guidebooks of Big 8 and the formats within those guides were the main drivers for those kind of audit opinions.

Vorhies (2005) summed up the functions of materiality, created by SarbanesOxley, as material errors, internal control deficiencies, acoounting estimates and fraud. He asserted that materiality judgement should cover all these four perspectives.

This paper presents the developments in materiality concept and builtup perspectives on it by reviewing a total of 35 references which consists of 22 theoretical, 6 of which is on national level and the rest on international, and of 13 practical, all of which is on international level. That the number of research in Turkey on application of materiality is so low and in international level is so limited indicates the constraints on storing such data and reaching those data sets.

According to Christiensen et al (2018) while International Auditing and Assurance Standards Board (IAASB) puts no obligation on audit reports 
to cover materiality issue, and Public Company Accounting Oversight Board (PCAOB) and American Institute of Certified Public Accountants (AICPA) do not mention such a requirement in their standards, regulatory organizations in Great Britain and Nederlands want to see the materiality issue in audit reports. That is why most of the literature on materiality in application aspect derives from those two countries.

Determining the materiality level subjectively by auditors is that important as it is not possible to apply a constant level of materiality in every kinds of audit. It would be beneficial for financial data users that the audit reports include materiality issue as it is in Great Britain and Nederlands.

\section{Kaynakça / References}

Acevedo, A. (2005).How Sarbanes-Oxley should be used to expose the secrets of discretion, judgment, and materiality of the auditor's report. Depaul Business \& Commercial Law Journal, 4(1), 1-53.

Barnes, J. (1973). More efficient auditing through an understanding of the materiaility concept. The Journal of Accountancy, Cilt(say1), 78-80.

Bates, H.L., Ingram, R. W. ve Reckers, P. M. J. (1982). Auditor-client affiliation: The impacton "materiality" A study of the effect of audit or rotation on materiality judgments. Journal of Accountancy, 1, 60-63.

Bennett, G. B. ve Hatfield, R. C. (2017). Do approaching deadlines influence auditors' materiality assessments?. Auditing: A Journal of PracticeE Theory, 36(4,) 29-48.

Blokdijk, H., Drieenhuizen, F., Simunic, D. A. ve Stein M. T. (2003). Factors affecting auditors: assessments of planning materiality. Auditing: A Journal of Practice\& Theory, 22(2), 297-307.

Bozkurt, N. (2018). Muhasebe denetimi. (8.bask1), İstanbul: Alfa Basım Yayınları

Brody, R., Lowe, D., ve Pany, K. (2003). Could \$51 million be immaterial when Enron reports income of $\$ 105$ million?. Accounting Horizons, 17(2), 153-160.

Budescu, D., Peecher, M., ve Solomon, I. (2012).The joint influence of the extent and nature of audit evidence, materiality thresholds, and misstatement type on achieved audit risk. Auditing: A Journal Of PracticeETheory, 31(2), 19-41. 
CanadianInstitute of Chartered Accountants (CICA) (1978). Materiality in auditing: an audit technique study (6.bsk). Toronto.

Chen, S., ve Tsay, B. (2017). Refer to materiality as a legal concept. Journal Of Corporate Accounting \& Finance, 28(2), 55-61.

Chewning, E. G., Wheeler, S. W. ve Chan C. K. (1998).Evidence on auditor and investor materiality thresholds resulting from equity-for-debt swaps.Auditing: A Journal of PracticeETheory, 17(1), 51-53.

Christensen, B. E., Eilifsen, AA., Glover, S. M. ve Messier, J. W. F. (2018, 5 Şubat). Materiality disclosures and their effect on investors' decisions.[Blog Yazısı], Columbia Law School's Blog On Corporations And The Capital Markets. 02 Ocak 2019 http://-clsbluesky.law.columbia.edu/2018/02/05/the-effect-of-materiality-disclosures-oninvestors-decisions/ adresinden erişilmiştir.

Cho, S., Hagerman, R. L., Nabar, S., ve Patterson, E. R. (2003).Measuring stockholder materiality. Accounting Horizons, 17(1), 63-76.

Comunale, C. L., ve Sexton, T. R. (2005). A fuzzy logic approach to assessing materiality. Journal of Emerging Technologies in Accounting, 2(1), 1-15.

Cömert, N. (2012). Uluslararası denetim standartları kapsamında önemlilik düzeyinin belirlenmesinde kullanılabilecek yöntemler. ISMMMO Mali Çözüm, 109, 47-68.

Çakıcı, C. (2002). Temel muhasebe varsayımları ve muhasebe politikalarına yön veren kavramlar. Öneri, 17, 69-76.

Çil, S. (2003). Denetimde kanıt seçmede örnekleme ve diğer yöntemlerin kullanımı ve ISA No.530. GÜTTEF Dergisi, 2, 1-21.

Dutta, S., ve Graham, L. (1998). Considering multiple materialities for account combinations in audit planning and evaluation: a cost efficient approach. Journal of Accounting, Auditing \& Finance, 13(2), 151-171.

Douglas, R. (2017). Quantitative materiality disclosure and the impact on investor decisionmaking and perceptions of audit quality. Masters thesis. The University of Canterbury, Canterbury.

Eilifsen, AA. ve Mckee, T. E. (2000). What is all the fuss about materiality?. Ohio CPA Journal, 59(4), 49-52.

Eilifsen, AA. ve Mckee, T. E. (2000). Current materiality guidance in auditing. The CPA Journal. 70(7), 54-57. 
Emby, C.,ve Pecchiari, N. (2013). An empirical investigation of the influence of qualitative risk factors on Canadian auditors' determination of performance materiality. Accounting Perspectives, 12(4), 281299.

Erdoğan, N. (2007). Muhasebe denetiminde niteliksel önemliliğin gerekliliği. Muhasebe ve Finansman Dergisi, 31, 112-119.

Estes, R.,ve Reames, D. (1988). Effects of personal characteristics on materiality decisions: A multivariate analysis. Accounting And Business Research, 18(72), 291-296.

Kamu Gözetimi Kurumu. (2018). Finansal raporlamaya ilişkin kavramsal çerçeve. 02 Ocak 2019 tarihinde http://www.kgk.gov.tr/Portalv2Uploads/files/Duyurular/v2/TFRS/Finansal\%20Raporlamaya\%20\%C4\%B0li\%C5\%9Fkin\%20Kavramsal\%20\%C3\%87er\%C3\%A7e ve\%20.pdf adresinden erişilmiştir.

Iskandar, T., ve Iselin, E. (1999). A review of materiality research. Accounting Forum, 23(3,) 209-239.

Jacoby, J. ve Levy, H. B. (2016). The materiality mystery-The gap in GAAS. The CPA Journal,Temmuz, 14-18.

Joldos, A. M., Stanciu, I. C. ve Grejdan,G. (2010). Pillars of the audit activity: materiality and audit risk. Annals of the University of Petroşani, Economics, 10(2), 225-238.

Jordan C.E., Clark S. J. ve Pate G.R. (1995). Materiality guidelines for modifying audit reports. Journal of Accountancy, 180(1), 89-92.

Karavardar, A. (2014). Grup denetimlerinde bileşen önemlilik düzeylerinin belirlenmesinde GUAM modeli: MACM modeliyle karşılaştırmalı bir uygulama. Mali Çözüm Dergisi, 124, 149-178.

Kesimli, İ. (2018). External auditing and quality.In Accounting, finance, sustainability, governanceEfraud: theory and application. Singapore: Springer

Kızılgöl, Ö. ve İşgüden, B. (2011). Denetim riskinin belirlenmesinde mesleki yargının denetçiler tarafından kullanılması. MÖDAV, 4, 1-33.

Mcconnell, D. K. ve Schweiger, C. H. (2007). Implementing the new AS6 risk assessment audit standards. The CPA Journal, Haziran, 20-26.

Messier, W., Martinov-Bennie, N., ve Eilifsen, AA. (2005). A review and integration of empirical research on materiality: two decades later. Auditing: A Journal of PracticeETheory, 24(2), 153-187. 
Morris M. H. ve Nichol, W. D. (1988). Consistency exceptions: materiality judgments and audit firm structure. The Accounting Review 13 (2), 237-254.

Pany K. ve Wheeler S. (1989). Materiality: An inter-industry comparison of the magnitudes and stabilities of various quantitative measures. Accounting Horizons, 3(4), 71-78.

Park J. J. (2009). Assessing the materiality of financial misstatements. The Journal of Corporation Law, 34(2), 514-565.

Porter, B., Simon, J., ve Hatherly, D. (2003). Principles of external auditing. (2.bsk). Chichester: Wiley.

Price, R.,ve Wallace, W. (2002). An international comparison of materiality guidance for governments, public services and charities. Financial Accountability and Management, 18(3), 261-289.

Raman K. K. ve Van Daniker R. P. (1994). Materiality in government auditing. Journal of Accountancy, 177(2), 71-76.

Read, W. J., Mitchell J. E. ve Akresh, A. D. (1987). Planning materiality and SAS NO.47. Journal of Accountancy, Aralık, 72-79.

Roberts, R. W. ve Dwyer, P. D. (1998). An analysis of materiality and reasonable assurance: Professional mystification and paternalism in auditing. Journal of Business Ethics, 17, 569-578.

Seidler, L. J. (1999). Materiality decisions in the computer age. The CPA Journal, Mayis, 22-24.

Socol, A. (2008). Materiality in the context of an audit between Professional judgment and subjectivism. Annals of the University of Petroşani, Economics, 8(2), 209-216.

Street, D. L., Nichols, N. B., ve Gray, S. J. (2000). Assessing theacceptability of international accounting standards in the U.S.: An empirical study of the materiality of U.S. GAAP reconciliations by nonU.S.companies complying with IASC standards. The International Journal of Accounting, 35(1), 27-63.

Taş O. ve İnaltong, C. (2015). Bağımsız denetim sürecinde önemlilik düzeyinin belirlenmesi ve bir uygulama. Vergi Dünyası, 401, 73-89

Terzi, S. (2012). Önemlilik değerlendirmesinde bulanık mantık yönteminin kullanımı ve bir uygulama. Muhasebe ve Denetime Bakış, Eylül, 125-149. 
Thomas, C. W. ve Krogstad, J. L. (1979). Materiality guidance for auditors. The Journal of Accountancy, 14(2), 74-77

Tuttle B., Coller M. ve Plumlee R. D. (2002). The effect of misstatements on decisions of financial statement users: an experimental investigation of audit materiality thresholds. Auditing: A Journal of PracticeETheory, 21(1), 11-27.

Vaassen, E. H. J. (1994). Auditors' decision processes in audit planning stage materiality judgments. Faculty of Economics and Business Administration, Doctoral Thesis, Ekim, University of Limburg.

Vorhies, J. B. (2005). The new importance of materiality. Journal of Accountancy, May1s, 53-58.

Waters, J. M. ve Tiller, M. G. (1997). Auditor's materiality thresholds: some empirical findings based on real data. American Business Review, 15(2), 115-119.

\section{Kaynakça Bilgisi / Citation Information}

Memiş, M. Ü. ve Okşaş, M. (2019). Denetimde önemlilik kavramı üzerine bir literatür taraması. OPUS-Uluslararası Toplum Araştırmaları Dergisi, 12(18. UíK Özel Sayıs1), 1030-1051. DOI: 10.26466/opus.583802 